\title{
Cut the weeds and dig up the roots: clip-and-snare assisted endoscopic mucosal resection of a rectal neuroendocrine tumor
}

Endoscopic submucosal dissection (ESD) has been the preferred treatment of small gastrointestinal neuroendocrine tumors (NETs) ( $\leq 10 \mathrm{~mm})$ without muscularis propria invasion [1]; however, the requirements of special instruments and complex skills have limited its widespread application [2]. In this regard, we developed a simple clip-and-snare assisted endoscopic mucosal resection (CS-EMR) technique for complete removal of a rectal NET ( $\triangleright$ Video 1 ).

A 35-year-old man was referred for endoscopic treatment of a small rectal NET $(6 \mathrm{~mm})$. Because the NET was seen on colonoscopy to have a flat subepithelial surface ( $\mathbf{F i g . 1}$ a) and was evaluated on endoscopic ultrasonography (EUS) as not showing invasion of the muscularis propria, CS-EMR was used to achieve complete resection. As the transparent capcovered single-channel endoscope, along with a pre-anchored snare, entered the rectum to target the tumor, a clip was inserted through the working channel of the endoscope and was used to grasp the mucosa adjacent to the tumor ( Fig.1 b). When the NET had been well lifted by the clip and transformed into a "pedicle polyp," the snare was released from the endoscope and completely enveloped the root of the NET ( $\triangleright$ Fig.1 c). The NET was fully excised using a blended electrosurgical current ( $\mathbf{F i g . 1 d}$ ), leaving a clean surgical wound ( $\triangleright$ Fig. 1 e). The wound was immediately closed by the lifting clip and application of a further clip ( $\triangleright$ Fig. 1f). Histological examination of the resected specimen revealed a G1 NET with negative margins ( $>$ Fig. 2 ).

Unlike the previously reported graspand-snare EMR, which requires a dualchannel endoscope to deploy a snare and

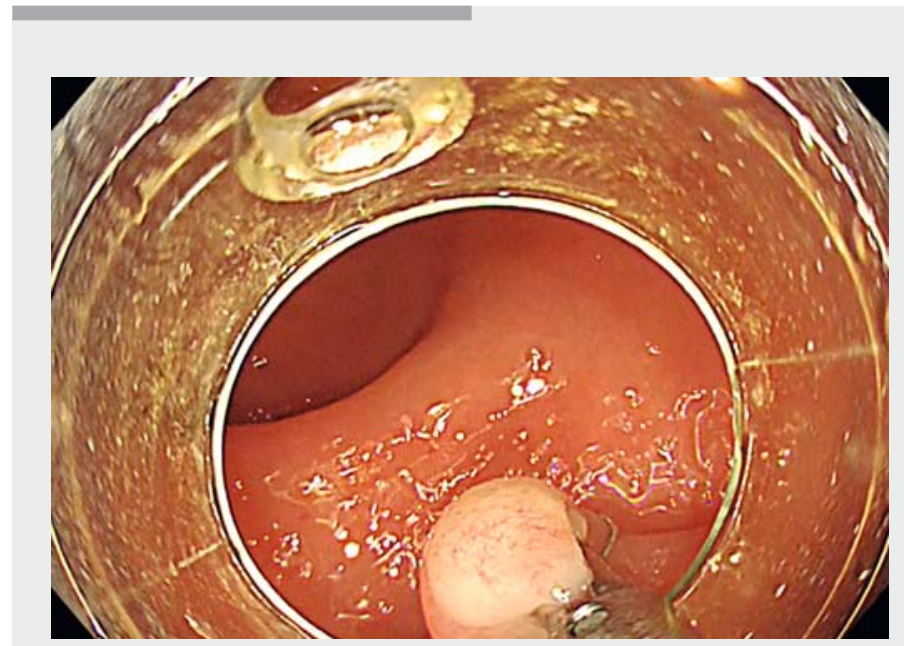

Video 1 Clip-and-snare assisted endoscopic mucosal resection of a rectal neuroendocrine tumor. A reopenable clip is used to lift the flat lesion away from the muscularis propria, allowing a preloaded snare to encircle the resulting "polyp" root below the clip and endoscopically resect it. The surgical wound is closed by clips.

a biopsy forceps through each channel [3], this CS-EMR needs only a single-channel endoscope. Unlike with the "underwater" EMR technique, which may be affected by blind vision once bleeding occurs [4], the CS-EMR has no risk of causing bleeding before resection. Therefore, the easy and safe CS-EMR technique is a promising alternative to replace ESD in the treatment of small NETs.

Endoscopy_UCTN_Code_TTT_1AQ_2AD

\section{Acknowledgments}

This study was supported by the Natural Science Foundation of Liaoning Province (No.2019-ZD0932) and the Project of Department of Education, Liaoning Province (No. LZ2019019).

\section{Competing interests}

The authors declare that they have no conflict of interest.

The authors

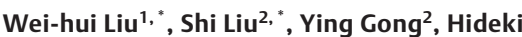
Kobara $^{3}$, Shi-Bin Guo ${ }^{2}$, Jian Gong ${ }^{2}$

1 Department of Gastroenterology and Hepatology, Sichuan Academy of Medical Sciences \& Sichuan Provincial People's Hospital, Chengdu, Sichuan, China

2 Department of Gastroenterology, The First Affiliated Hospital, Dalian Medical University, Dalian, Liaoning, China

3 Department of Gastroenterology and Neurology, Faculty of Medicine, Kagawa University, Kita, Kagawa, Japan 

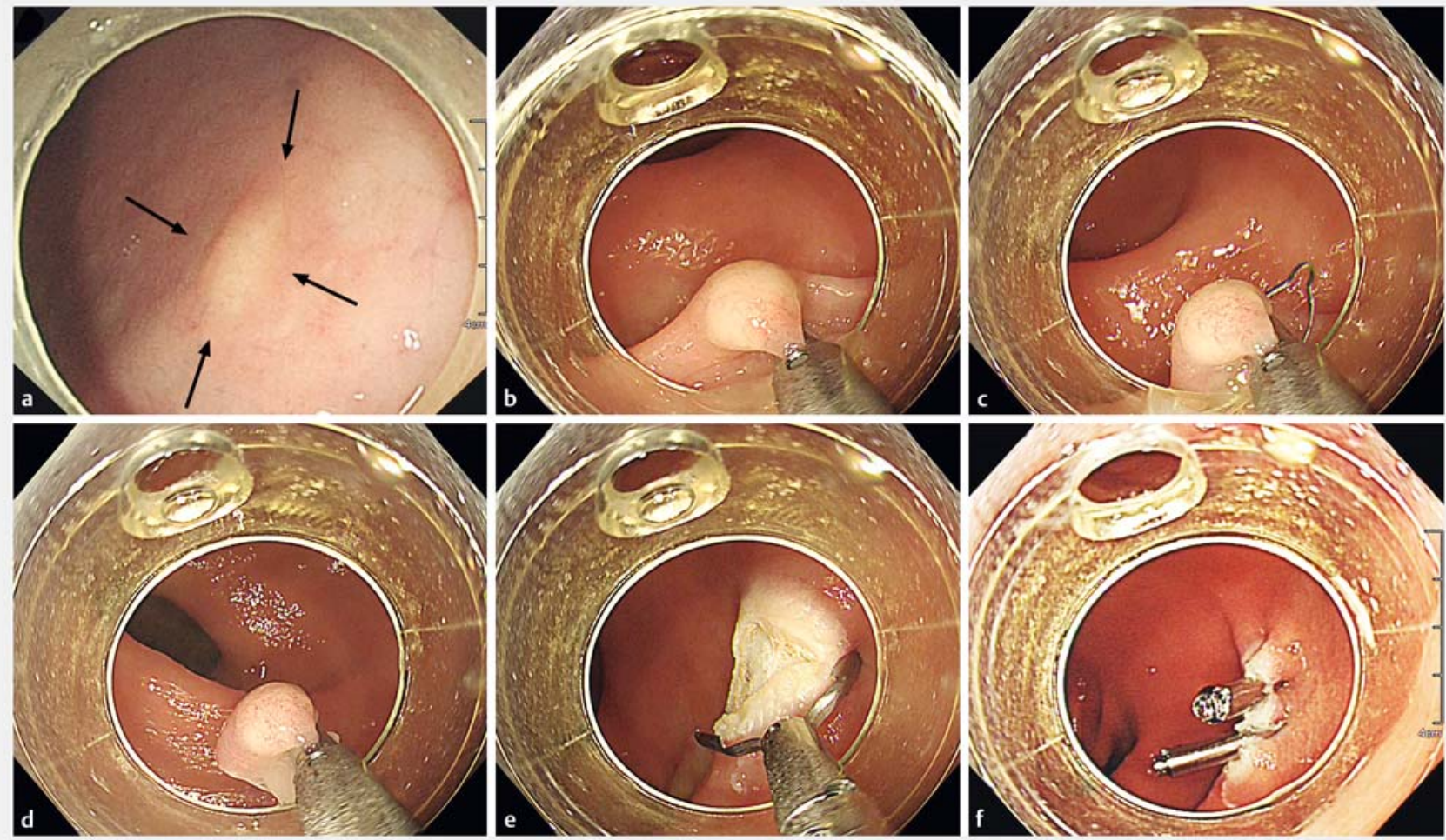

Fig. 1 Endoscopic treatment of a rectal neuroendocrine tumor (NET) using the clip-and-snare assisted endoscopic mucosal resection (CSEMR) technique. a Colonoscopy showed a subepithelial lesion (arrows) with typical NET features of poorly protruded surface and superficial yellowish mucosa. b The clip gently clamped and pulled the lesion toward the endoscope to separate it from the muscularis propria. $\mathbf{c}$ The snare was advanced beneath the clip and tightly trapped the root of the lesion. $\mathbf{d}$ The lesion was resected with standard polypectomy settings. e A clean surgical wound was displayed. f The surgical wound was perfectly closed with only two clips.

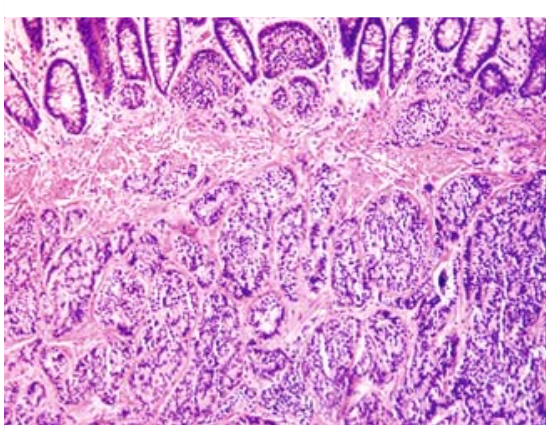

> Fig. 2 Histological appearance confirming the resected specimen as a $\mathrm{G} 1$ neuroendocrine tumor with negative margins.

\section{Corresponding author}

\section{Jian Gong, MD}

Department of Gastroenterology, The First Affiliated Hospital, Dalian Medical University, 222 Zhongshan Road, Dalian, Liaoning

116011, P. R. China

gongjian@dmu.edu.cn

\section{References}

[1] Park SS, Han KS, Kim B et al. Comparison of underwater endoscopic mucosal resection and endoscopic submucosal dissection of rectal neuroendocrine tumors (with videos). Gastrointest Endosc 2020. doi:10.1016/j. gie.2019.12.039

[2] Oung B, Walter T, Hervieu V et al. Nonampullary duodenal subepithelial neuroendocrine tumor removed R0 by endoscopic submucosal dissection with double clips and rubber band traction. VideoGIE 2019; 4 : 570-573

[3] Shetty A, Suarez AL, Dufault DL et al. Endoscopic mucosal resection with grasp-andsnare technique for challenging lesions. Gastrointest Endosc 2016; 84: 738-739

[4] Yoshii S, Hayashi Y, Matsui T et al. "Underwater" endoscopic submucosal dissection: a novel technique for complete resection of a rectal neuroendocrine tumor. Endoscopy 2016; 48 (Suppl. 01): E67-E68

\section{Bibliography}

Endoscopy 2021; 53: E13-E14

DOI $10.1055 / \mathrm{a}-1163-7140$

ISSN 0013-726X

published online 29.5.2020

(c) 2020. Thieme. All rights reserved.

Georg Thieme Verlag KG, Rüdigerstraße 14, 70469 Stuttgart, Germany

\section{ENDOSCOPY E-VIDEOS}

https:/|eref.thieme.de/e-videos

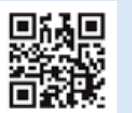

Endoscopy E-Videos is a free access online section, reporting on interesting cases and new

techniques in gastroenterological endoscopy. All papers include a high quality video and all contributions are freely accessible online.

This section has its own submission website at

https://mc.manuscriptcentral.com/e-videos 